hydrolysis of dietary proteins has also been demonstrated [Butler et al (1984) IAOCS 61, 916920].

The activity of NAP, DDP IV and $\gamma \mathrm{GT}$ was measured in 3 sites of the small intestine (duodeum, jejunum and ileum) of 24 piglets weaned at $21 \mathrm{~d}$ of age and slaughtered 5 weeks later fed 1 of the 3 experimental diets based on maize or sorghum containing 0.03 or $1.36 \%$ of tannin expressed as catechin (table I). It was found that the specific activity of all peptidases increased from the duodenum to the ileum $(P<$ 0.05 ). Peptidase activity was affected in piglets fed the sorghum-based diets, but only a significant decrease $(P<0.01)$ of $\gamma$ GT was observed. The activity of alkaline phosphatase decreased linearly but not significantly. We suggest that tannin, which induced a decrease in the apparent digestibility of dietary nitrogen, has an effect on the enterocyte of the small intestine of the piglet, disturbing the process of protein hydrolysis and absorption through the membrane.

\section{Involvement of L-arginine/nitric oxide pathway in the absorption of calcium in} the rat small intestine. $R$ Schleiffer, $M$ Galluser, F Raul (INSERM U61, Biologie Cellulaire et Physiopathologie Digestives, 3, avenue Molière, 67200 Strasbourg, France)

Nitric oxide (NO) is produced enzymatically in vivo from L-arginine. It was originally identified as the main endothelium-derived relaxant factor and is now recognized as a second messenger mediating a variety of biological processes, including platelet aggregation, neurotransmission and immunological reactions [Moncada et al (1991) Pharmacol Rev 43, 109-142]. Recent evidence indicates that enterocytes also produce NO [Blachier et al (1991) Biochem Biophys Acta 1092, 304-310]. The aim of this study was to determine the involvement of the L-arginine/NO pathway in intestinal calcium absorption.

An inhibitor of NO production ( $\mathrm{NG}$-nitro-L-arginine methyl ester, L-NAME) and sodium nitroprusside (SNP), a donor of NO, were perfused in adult Wistar rats anesthetized with ethyl carbamate. An intestinal segment (duodenum + proximal jejunum) was perfused by both intraluminal and vascular routes [Scheiffer et al (1993) Biomed Pharmacother 47, 19-23]. The intraluminal solution ( $\mathrm{NaCl} 155 \mathrm{mM}+\mathrm{CaCl}_{2} 1.25 \mathrm{mM}$ ) contained ${ }^{45} \mathrm{Ca}$ and was perfused at a flow rate of $0.2 \mathrm{ml}^{\circ} \mathrm{min}^{-1}$. Calcium absorption was quantitated by measuring ${ }^{45} \mathrm{Ca}$ appearing in the superior mesenteric vein. The drugs were intravenously perfused at a flow rate of $0.1 \mathrm{ml}^{\circ} \mathrm{min}^{-1}$. Mesenteric blood flow (MBF) and mean arterial pressure (MAP) were also measured throughout the experiment. Perfusion of L-NAME $(0.123$ $\mu \mathrm{mol}$. $\mathrm{min}^{-1}$ ) resulted in an increase in MAP (+ $17 \mathrm{mmHg}$ ) and a decrease in MBF (30\%). Calcium absorption was decreased from basal $0.21 \pm 0.02$ to $0.15 \pm 0.01 \mu$ mol$^{\circ} \bullet^{-1} n^{-1} \cdot \mathrm{kg}^{-1}$ body weight within $20 \mathrm{~min}$ of L-NAME perfusion. Inversely, SNP $\left(0.032 \mu \mathrm{mol}^{\circ} \mathrm{min}^{-1}\right)$ decreased MAP and increased MBF. An increase $(30 \%)$ in calcium absorption was observed within 20 min of SNP perfusion.

These experiments suggest that the level of a product of the L-arginine/NO pathway may be involved in the regulation of calcium absorption in the rat small intestine.

Is gut permeability affected by age and soyabean antigenicity in the preruminant calf? P Branco Pardal 1, JP Lalles 1, F André ${ }^{2}$, E Delval ${ }^{3}$, R Toullec ${ }^{1}$ ( 1 INRA, Laboratoire du Jeune Ruminant, 65, rue de Saint-Brieuc, 35042 Rennes, Cedex; 2 INSERM, Centre Hospitalier Lyon-Sud, Pierre-Bénite; ${ }^{3}$ INRA, Station de Recherche sur la Nutrition des Herbivores, 63122 SaintGenès-Champanelle, France)

Various small marker probes such as xylose, $\mathrm{Cr}$ EDTA and mixtures of oligosaccharides are used to assess the permeability of the gut in health and disease, but the actual mechanisms of their uptake are still unclear. Dual marker tests like lactulose/mannitol [André et al (1990) HepatoGastroentero/ 37 (suppl II), 113-117] rather than single probes are to be preferred to overcome extraneous influences, including gastric emptying rate or intestinal transit on marker absorption. Here, we assessed intestinal permeability using different markers in veal calves, which were fed milk replacers differing in protein source and antigenicity.

Twenty-eight male Holstein calves were placed in cages and fed various diets from 6 weeks of age until slaughter. Protein milk replacers was provided by either skim-milk pow- 